\title{
Global initiatives in waste gasification
}

\author{
S. Petters ${ }^{1}$, K. Mauthner ${ }^{2} \&$ K. Tse ${ }^{3}$ \\ ${ }^{I}$ guo - Business Development Consult, Austria \\ ${ }^{2}$ KatyushaTec, Austria \\ ${ }^{3}$ Bestrong International Ltd., Hong Kong
}

\begin{abstract}
Municipal Solid Waste (MSW) residues usually occur in a combination of wet and combustible forms, requiring separate or sequential treatments by bio- and thermo-chemical processes, rather than incinerating under a mixture of auxiliary fuel addition. Thermo-chemical decomposition of poor carbonaceous fuels into energy-rich producer gas has been demonstrated with biomass feedstock technically mature over more than 5 years, now at 30-50GJ solid fuel consumption and is currently ramped up in Gothenburg (SE) at a 120GJ feedstock scale.

Still lacking in financial self-sufficiency, Vienna's latest state of the art Pfaffenau incineration plant, where an integrated ADOS facility for commercial F\&K waste is used to cover auxiliary fuel demand and excess refuse derived fuel (RDF) fractions are stored for evening out seasonal patterns, has inspired us to look at waste gasification as a more resource-efficient approach than incineration.

From publicly available data we could summarize that there are almost 1.5 dozen initiatives of waste gasification globally. Some of them even target waste hydrocarbon transformation into transportation fuel hydrocarbons, which seems to be the more value-adding downstream usage path than simply combined heat and power (CHP).
\end{abstract}

Keywords: waste to value, carbon capture for use, resource efficiency, $\mathrm{CO}_{2}$-recycling, chemical synthesis fuel, innovation implementation, consortium, economic scale, incineration, gasification.

\section{Introduction}

A generally applicable method of waste gasification seems to require a substantial tolerance range for the fuels' quality. Because the poorer a local population, the lower the heating value of final organic residues gets and makes thermo-chemical 
treatment process control vulnerable. Although there are some best practice incineration examples out in the field, the cost of that are not affordable for the majority of the world's population. Further ongoing debates about $\mathrm{CO}_{2}$ effectiveness of such Waste to Energy installations seem to have inspired several people to look at waste gasification as a more resource efficient approach than incineration.

The methods spread from plasma, pyrolysis liquor, and steam reforming to indirect gasification under steam. Some regulatory regimes however even prohibit formation of any sulfur, chlorine, nitrogen, etc. oxide complexes from direct contact of unconverted waste with combustion, limiting process choices [1].

\section{Thermo-chemical MSW to fuel transformation projects}

\subsection{Klean Industries Inc. (CAN)}

Klean holds out to have conducted 500+ plant installations worldwide that are economically self-sufficient on a standalone basis by employing both catalytic and non-catalytic processes to transform pyrolysis, gasification and liquefaction in waste streams to convert municipal solid wastes into clean electrical energy and transform petroleum based waste streams (such as plastics and tires) into valuable carbon and oil commodities for reuse - "reinventing oil with conservation and energy efficiency" [2].

\subsection{AlterNRG (US)}

AlterNRG uses Westinghouse plasma technology gasification for organic matter with its largest plant $\left(80,000 \mathrm{t} / \mathrm{a} \mathrm{MSW} / 25 \mathrm{MWh}^{-1}\right.$ chem $)$ in Utashinai, Hokkaido, Japan at a Hitachi Metals plant for process heat from the combustion of high synthesis gas content product gas. Further a $30 \mathrm{t} / \mathrm{d}$ medical and hazardous waste plasma gasification treatment system in Shanghai, $(\mathrm{CN})$, has recently been launched in collaboration with GTS Energy [3].

Also a larger gasifier was recently delivered to UK-Tees Valley $(950 \mathrm{t} / \mathrm{d}$ $\mathrm{MSW} / 100 \mathrm{MWh}^{-1}$ chem) to produce gross $50 \mathrm{MW}^{\mathrm{h}-1}{ }_{\mathrm{el}} / 33.5 \mathrm{MW}_{\text {net }}$ for air products, scheduled for commissioning 2014.

\subsection{Enerkem (US)}

The waste to biofuel plant in Westbury Quebec (CAN) is a demonstration facility for 5 million litre/a ethanol from Municipal Solid Waste (MSW) and/or waste wood or harvest residues. Sorted dried feedstock is gasified in a stationary fluidized bubbling bed reactor followed by gas cleaning for catalytic conversion into final chemical synthesis products. Currently first commercial 38 million litre plant in Edmonton, Alberta (CAN) is under construction. Furthermore, two commercial plants of identical size are planned in Pontotoc, Mississippi (US), receiving \$50 mio DOE grant plus $\$ 80$ mio USDA guarantee, as well as Varennes, Québec (CAN) [4]. 


\subsection{INEOS Bio and New Planet RE - JV (INPB) (CH)}

INPB develops a 3,5001/h cellulosic bio-ethanol plant from organic residues and/or MSW in Vero Beach, FL (US), based on INEOS Bio gasification process. This is a two-step, oxygen-blown technology starting by exposure of feed-stock to the heat in a lower chamber of the gasifier for further drying, followed by pyrolysis into a pyrolysis gas.

The pyrolysis gas passes through to the upper chamber where it is mixed with more oxygen, generating more heat from partial combustion. High temperature and residence time crack the pyrolysis gases to mainly carbon monoxide, hydrogen and some carbon dioxide.

No tars or aromatic hydrocarbons are present in the synthesis gas. Overall gasification reaction of biomass can be approximated: $8 \mathrm{CH}_{2} \mathrm{O}+\mathrm{O}_{2}>6 \mathrm{CO}+2 \mathrm{CO}_{2}$ $+8 \mathrm{H}_{2}$. The gasifier operates at slightly negative pressure. The formation of dioxins and furans is said to be suppressed by the reducing process atmosphere [5].

\subsection{Fulcrum Bioenergy (US)}

Fulcrum develops its Sierra BioFuels Plant, located in the Tahoe-Reno Industrial Center, in the City of McCarran, Storey County, Nevada; as first MSW to fuels plant, to produce approximately 10 million gallons of low-carbon, renewable fuel from MSW per year, apparently based on a solid carbonaceous fuel steam reforming counter flow gasification.

Fulcrum holds out to have entered into long-term, zero-cost MSW feedstock agreements with 'Waste Management' and 'Waste Connections' (two of the largest waste service companies in North America) and a fuel off-take agreement with Tenaska BioFuels.

SOP is scheduled for the end of 2015, making the Sierra BioFuels Plant one of the United States' first fully operational, commercial-scale MSW-to-biofuel productions by Fischer-Tropsch process from MSW gasification. Fulcrum further contemplates to have an already signed-up roll-out plan of further 23 plants across North America to process about $4 \%$ of garbage landfilled annually in the US. Four are said to be already are under development [6].

\subsection{Elementa Group Inc. (CAN)}

Elementa in Niagara-on-the-Lake (ON) uses an indirectly fired rotary kiln at a high temperature and non-oxidizing environment for its patented waste-to-gas conversion based on a solid carbonaceous fuel steam reforming process. For tar removal a University of Technology Vienna method was mutually applied [7].

The Pilot Plant in Sault Ste. Marie, proved concepts for the first commercial plant designed for $\sim 50000$ t/a MSW, scheduled to start early in 2014. For the time being the producer gas will be used for combined heat and power (CHP) electricity (only).

The pilot facility delivered very nice inorganic emission data, undercutting the most stringent standards' maxima by more than $50 \%$ [8]. 


\subsection{HVC waste processing (NL)}

HVC is a municipal service company owned by the 48 municipalities it services and already entertains 7 (conventional) WtE plants for a total of 1 mio t/a MSW. HVC also entertains one sewage sludge incineration plant for $380,000 \mathrm{t} / \mathrm{a}$ in Dordrecht and 1 dry biomass plant and in Alkmaar. Total green and food waste amounts to $80,000 \mathrm{t} / \mathrm{a}$ in the municipalities, for which a mixed (solids and sludge) feedstock batch digestion system had been installed. Inside "rotting houses" feedstock gets irrigated until leachate comes out at a ph of 5 through a perforated double floor bottom, to methanize in external tanks (similar to the Aikan Technology (DK)). Combustible solids can be screened out easily after this biogas process for a thermo-chemical treatment. The basic concept has already been tested in Petten facility at $1 \mathrm{MW}_{\text {chem }}$ feedstock demonstration.

Now Dahlman plans a $12 \mathrm{MW}_{\text {chem }}$ feed-stock plant at Alkmaar based on "local IP" technology, already subsidized in the development. The location allows future fuel mixes from demolition wood, over wet branches to dried sewage sludge. Investment will be $€ 22$ mio (50/50 public/private) driven by TKI (state gas utility supplier + NL $-\mathrm{SDE}+$ production FiT/electricity/gas subsidy) [9].

\subsection{Coskata Madison PA (US)}

Coskata owns a proprietary microorganism technology that converts nearly all of the chemical energy of a Syngas into desired end product fuels and chemicals. The fermentation process operates at low pressure and low temperatures, delivering cost and energy advantages over thermo-chemical pathways. Commercially available distillation and dehydration technologies efficiently separate the final product from the water stream exiting the bioreactor having several cost-savings measures designed in, including heat recovery and water recycling, reducing external energy and minimizing water consumption.

For the Syngas conversion from waste Coskata used plasma gasification at Westinghouse test facility during two years successful testing with wood waste and MSW. For soft-wood feedstock they quote a $43 \%$ energy yield ethanol conversion capability [10].

\subsection{ICM Gasifier Project, Harvey County KS (US)}

ICM tested thousands of tons of different types of waste, which included wood chips, wheat straw and refuse-derived fuel (this includes junk mail, cardboard and other paper products thrown away). The Harvey County facility likely would have needed to process 90 tons of trash per day - in lack of secured supply the test facility has been decommissioned again. ICM fixed bed gasifier project burned trash and converted it to synthetic gas, which can be used to generate power in industrial and commercial settings. ICM plans to try to market the technology in a different area, perhaps overseas [11]. 


\subsection{BioEnergy2020+ (TU - Vienna/Graz) (AUT)}

By now engineered several times by Repotech (AUT) is called Fast Internal Circulating Fluidized Bed (FICFB) Technology and enjoys a $>5$ years scale operation experience based on biomass in Güssing - having enabled the development of fully validated simulation models for bridging the gap between laboratory reactors at the university and scale light house plants in Güssing (AUT), Oberwart (AUT), Villach (AUT), Senden (GER), Gothenburg (SE). In Güssing the full scope of polygeneration including a FiT - Fuel synthesis from slipstreams of the producer gas had been demonstrated at laboratory scale. A 1 bbl/day synthetic diesel scale-up remake of this previous demonstration is pending for industrial partners' co-financing (estimated cost $\sim € 2.5 \mathrm{mio}$ ) - whereas there is no technical implementation risk left after the previous lab-scale results.

Due to unfavorable regime conditions and in spite of significant price increases for biomass experiments for processing waste fractions (from refuse derived fuel (RDF) to sewage sludge) in this steam driven fluidized bed dual reactor, allotherm gasification technology, had to remain limited to execution at laboratory scale. Promising results triggered plans to build a $2 \mathrm{MW}_{\text {chem }}$ demonstration reactor which would be readily designed for construction, but lacks financing so far (estimated cost $\sim € 3.5 \mathrm{mio}$ ) [12].

\subsection{GPA 500 counterflow pyrolysis (AUT)}

The Tettnang (GER) pilot plant works at $900^{\circ} \mathrm{C}$ heated externally by electricity and under sub-pressure in ceramic tubes with ceramic conveying screws. Recirculation of the liquid decomposition phase directly into the feedstock for gasification eliminates all liquid phase pyrolysis products in the $2^{\text {nd }}$ pass. The residual bio-char can either be used for soil replenishment - or in case of MSW feedstock, may be considered for catalytic $\mathrm{CO}_{2}$-splitting during hot-gas filtering. The process needs considerable water content, which can be contributed by feedstock moisture, for the reforming reaction of the product gas. Gas cleaning is designed with ceramic multiple tube filters for hot gas cleaning. Dust is periodically blown off the filter candles with compressed product gas and conveyed by screw to the outside. Product Gas from woody biomass comprises of $\sim 32 \%_{\text {vol }} \mathrm{CO}+27 \%_{\text {vol }} \mathrm{H}_{2}+15 \%_{\text {vol }} \mathrm{CH}_{4}+4 \%_{\text {vol }} \mathrm{C}_{\mathrm{x}} \mathrm{H}_{\mathrm{y}}$ and $3.5 \%_{\text {vol }} \mathrm{O}_{2}$ $+2.5 \%$ vol $\mathrm{N}_{2}+3 \%_{\mathrm{vol}}$ carbon dust. Final tar is removal by rapeseed oil, recycled into feedstock [13].

\subsection{EXA S.r.l. (IT)}

EXA states to have developed (and installed at a customer not wanting to be cited) a $1 \mathrm{MWh}^{-1}$ el $\mathrm{CHP}$ from biomass based on fluidized bed gasification supposedly put on line within 2013, enjoying a feed-in tariff of $€ 280 / \mathrm{MWh}^{-1}$ el. Their web-page is talking about opportunities to use this system also for Organic fractions of Organic waste; complaining however, that recycling does not enjoy the same support like ligneous or vegetable biomass [14]. 


\subsection{Energy Life Group S.r.l. (IT)}

This design and consulting company chose a Romana Maceri Centro Italia S.r.l. patent, designed at the end of 1990's to gasify garbage and, later time in 2004, tires for CHP power plants. Their RSU - DUALFuel $15.000^{\circledR}$ platform, valorizes separately liquid and solid fractions, obtained with the MSW treatment after selection and allows to exploit best the combustible power of the two separated fractions [15].

\subsection{EcoEng Environment S.r.I. (IT)}

This design and consulting company has delivered to Industria Laterizi Vogherese Spa. (ILV) a $25 \mathrm{MW}_{\text {therm }}$ double stage gasifier for a tunnel kiln and dryer feeding and contemplates to have inspired NYC to look at gasification technology as an alternative to the incineration of MSW already in 1994. The design is for a twostage plant, one that makes brick-shaped blocks of ground-up trash, after removing large metal objects and all ferrous - or iron-bearing - materials. The bricks are then loaded into a gasifier, a tall metal vessel. At the bottom, some of the bricks burn, providing the heat for the gasification. The device appears to be a counter draft fixed bed reactor from Mannesmann Italia with steam as gasification agent. The company's core competence seems to lie in the production of RDF briquettes from MSW [16].

\subsection{Castor and Pollux (SK)}

Castor Pollux engaging in project management and project financing (Pre-accession EU funds - PHARE and SAPARD; EU Structural Funds 2004-2006 such as SOP, OP, UPD) is in the process of implementing a plastic waste recycling technology in Slovakia for industrial plastic waste. Plastic waste can be refined and subsequently in the production process transformed into a liquid fuels components and used for energy purposes. The recycling is carried out by a thermo-catalytic cracking process of plastics (de-polymerization). The technology was recognized most notably during the Finals of The Energy World Leaders 2005 contest and won "Pollutec 2006 in Lyon Gold Medal in IV edition EEP Awards" [17].

\subsection{Dron Industries s.r.o. (SK)}

Dron developed technological equipment for processing rubber and plastic waste by cracking. The decomposition process takes place at $750^{\circ} \mathrm{C}$. The aim is to get sellable product from waste materials. The current pilot installation is for 15,000 t/a rubber and elastomeric waste, delivering 2,000 t/a pyrolisis gas; 6,000 t/a pyrolisis oil; 6,000 t/a pyrolisis char [18]. 


\subsection{JFE Engineering (JAP)}

JFE Engineering has been active in the field of Waste to Energy since 1968 with over 162 plant in Japan and so far 7 references outside. Recently JFE has developed a 310t/d RDF (from MSW) gasification technology, last awarded a contract for Albano (ITA) by COEMA, a special purpose company with SCA Group (largest private waste treatment service company in Rome). The original pilot plant is located in Fukuyama, with a 10 year operating track record.

The 3 level co-current fluidized bed carbonization/gasification/incineration arrangement separated by blowing steam/air/oxygen at upper/middle/bottom of the side-walls into the bed creates stagnation zones for the feedstock matter falling vertically into the bed and rising back into the volatilization zone again by the bed movement.

Energy use however so far has been limited to power or/and heat from burning the Syngas prior to final ash and flue gas cleaning. However, at the bottom slag can be extracted [19].

\subsection{KIT Bioliq ${ }^{\circledR}$ (GER)}

Bioliq ${ }^{\circledR}$ is a four stage process, designed to concentrate low energy density organic residues decentrally by fast pyrolysis followed by mixing with the powderized char into bioliqSyncrude ${ }^{\circledR}$. In second stage this intermediate undergoes central high pressure entrained flow gasification at over $1200^{\circ} \mathrm{C}$ and 80 bars, transforming into a tar-free synthesis gas (hydrogen: carbon monoxide), followed by a hot gas cleaning step to eliminate particles, chlorine and nitrogen complexes in order to synthesize fuels downstream by chemical synthesis processes, such as Fischer Tropsch [20].

\section{Conclusions}

\subsection{Experiences from biomass gasification}

Although gasification has been existing since 180 years, at first for the production of "town gas" and since 90 years for producing synthetic chemicals, biomass has been giving the hardest challenges to gasification. Looking at the sites developed worldwide, there have been three approaches. Either fuel was prepared to make it more coal like for entrained flow gasification, or all kinds of specific low scale, bed based gasification arrangements were developed, all allowing allotherm generation of the process heat. Plasma gasification may be seen as a third option, however, depending on availability of cheap electricity.

Biomass gasification's USP is smaller scale capability, which coal gasification can hardly reach economically. Coal gasification hourly feed-stock typically ranges in the order of 500-1,800GJ. For MSW organic residues this would equal about $50-180 \mathrm{t} / \mathrm{h}$ at an average of $10 \mathrm{GJ} / \mathrm{t}$ heating value [21].

MSW usually coming at $40-60 \%$ organic content, whereof $1 / 3$ only may be RDF, while $2 / 3$ advising bio-chemical stabilization prior to thermo-chemical 
remediation of sludge residues, may require a thermo-chemical feedstock capability per hour of 20-120GJ, equaling 2-12t/h at a mean LHV of $10 \mathrm{GJ} / \mathrm{t}$ [22].

This represents a range, where Steam Driven Indirect, Fast Internal Circulating Fluidized Bed (SDI-FICFB) gasification of biomass has developed a notable technical performance track record over the last 5 years. The decisions of Swede Gas and GDF-Suez to use SDI-FICFB Technology for their Substitute Bio Gas (SBG) initiatives may be seen giving direction for larger bio-refinery applications with rather chemical than final energy outputs. Goteborg Gas as NER300 beneficiary and GDF-Suez as a major utility supplier in a large EU member state had come to that decision after serious evaluations and considerations [23, 24]. The Technology Readiness Level (TRL) for this biomass gasification can nowadays be set at level 9 .

\subsection{Performance criteria}

Most experience reports from biomass gasification operations have stressed that:

a) mechanical problems in the feedstock transport systems and

b) tar/ash separation and removal from the product gas, as well as

c) fine particles in the fuel gas for the CHP engines represent the most downtime root causes. By the way, Choren's difficulties to satisfy their shareholders had stemmed from:

i) fuel variability sweeping through the whole process chain

ii) adverse effects from (originally intentionally allowed) ash slagging (for corrosion protection of the reactor inside

iii) increasing biomass prices throughout the project phase (also due to the competition from EEEG CHP subsidies) have been frustrating economic success.

Geographical extension of biomass gasification however so far mainly reflects the subsidy regimes that had been a condition precedent, as none of the so far explored usage paths had proven economic at arms' length market prices for fuel and output.

Only as already demonstrated in a Polygeneration's part-use of the available hydrogen-/carbon-monoxide fractions from a producer gas SDI-FICFB Gasification, chemical synthesis gas output could unlock higher level planes in the waste to value adding pyramid from abandoned organic residues [25].

\subsection{Advantages of SDI-FICFB gasification}

- No direct combustion of raw fuel due to the oxygen free atmosphere in the volatilization reactor, transforming fuel into energy, induced by the circulating bed as heat transfer medium;

- therefore fuel contaminants are released as hydrides into the product gas, from where they can be separated out rather as valuable chemicals than complex pollutants in the case of $\mathrm{O}_{\mathrm{x}} \mathrm{s}$;

- this two-stage process needs to be operated at temperatures below the ashsoftening temperature of the fuels inorganic fractions and therefore stays below 
$1000^{\circ} \mathrm{C}$, minimizing slagging, preserving plant components and allowing $\mathrm{NO}_{\mathrm{x}}$ lean combustion of the char under regular air;

- compared to EFG (entrained flow gasification) SDI-FICFB gasification does neither need narrow range fuel drying and pulverizing, nor pure oxygen separation from air, and has less waste temperature from cooling the product gas and therefore a slightly more favorable energy balance.

\subsection{Disadvantages of SDI- FICFB gasification versus EFG}

- Throughput restraints due to lower temperatures and pressure accounting for lower reaction speeds;

- energetically quite significant $\mathrm{CH}_{4}$ and $\mathrm{C}_{\mathrm{x}} \mathrm{H}_{\mathrm{y}}$ product gas contents, which however do not matter in any CHP downstream use but need post refining by additional processing steps in case of desired $100 \%$ downstream chemical synthesis into storable products to avoid losing added value from not using the energy output as often the case with CHP;

- in a world driven by quantitative growth strategies (more of the same = the bigger the better) large plant engineering firms have not prevalently taken up on SDI-FICFB gasification (yet).

\subsection{Methane content in the producer gas}

As demonstrated in example 2.7 holistic waste treatment approach should pre- or parallel-treat the fermentable fractions separately, delivering a methane stream. From all existing results organic matter gasification it appears that RDF fractions of MSW tend to increase the methane content in the producer gas of non-pressurized, below $1200^{\circ} \mathrm{C}$ operating gasifiers. This burdens the available CO fraction and lowers $\mathrm{H}_{2}$ :CO ratio synthesis gas outputs [26]. Methane is one of the thermally most stable molecules. Its $\mathrm{C}-\mathrm{H}$ bond's dissociation energy (E_436kJ/mol) is one of the highest amongst all organic complexes.

Over the last decade thermo-catalytic extraction of highly surface active crystalline carbon from methane had been developed in material science. As a by-product, hydrogen is released at just $55 \%$ of the endothermic energy requirement conventional Steam Methane Reforming (SMR) needs [27].

a) Our proprietary "dry thermo-catalytic" dissociation of hydrocarbon gases co-produces hydrogen plus highly surface active carbon-powder at determinable morphologies for further use. We therefore call it a Carbon Capture for Use (CCU) process [28].

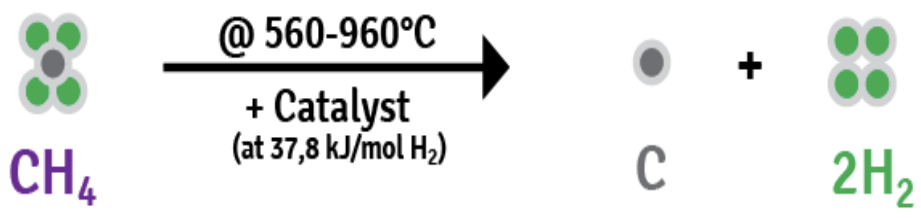

Figure 1: Co-production of carbon and hydrogen. 
b) This hydrogen production was originally developed for inorganic material composites. The nano carbon later had also been applied to various polymer composites. However, time to market for new special materials is undeterminable for anyone not having reasonable application market placement power [29].

c) As it has been shown in the cement industry, $\mathrm{CO}_{2}$ can be split over carbon under heat into $\mathrm{CO}$, particularly of interest, wherever sufficient unused waste heat potential is available. The Boudouard reactor such actually transforms thermal waste energy by recycling $\mathrm{CO}_{2}$ back into chemical energy [30].

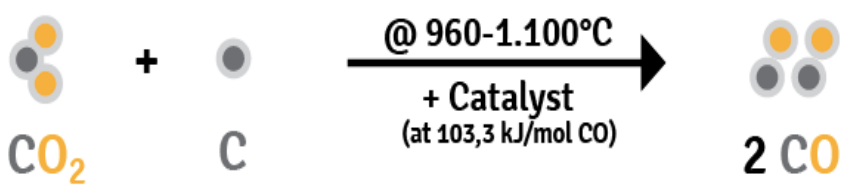

Figure 2: Captured carbon use as refining intermediate.

To optimize the achievable value from decomposition gas of organic matter, the Methane fractions from fermentation and $<1000^{\circ} \mathrm{C}$ low pressure gasification can be split by integration of dry thermo-catalytic carbon capture into an organic waste treatment system to deliver a synthesis gas of controllable $\mathrm{H}_{2}: \mathrm{CO}$ ratio. Waste to synthesis gas allows an additional level plane within the value adding pyramid from low grade combustible and fermentable waste, delivering roughly $1 / 2$ a barrel crude's value per $\mathrm{MW}_{\text {chem }}$ in the feedstock, without subsidies [31].

\subsection{Economic benchmarking}

Austria is quite well known for its high Waste to Energy standards, having diminished landfilling to $<6 \% \%_{\mathrm{wt}}$ of its wastes. While earlier installations from the 1990 's require auxiliary fuels to compensate for not separated wet fractions, the latest installation in "Pfaffenau" uses the biogas from commercial food and kitchen waste's anaerobic digestion as "autothermal" heat energy source. Since this allows some stock building of RDF fractions over the year, operations can be adjusted to a certain extent to district heating demand situations to avoid idling losses. But comparing its economic performance with a polygeneration configuration including Synthetic Fuel output or even its full flexibilization to up to $100 \%$ Synthetic Fuel output, the added value can be almost tripled:

Therefore the various initiatives into a substitution of waste incineration by gasification techniques deem understandable, particularly in non-subsidized electricity off-take regimes. 
Table 1: Waste to Energy benchmarking.

\begin{tabular}{|c|c|c|c|c|}
\hline $260,000 \mathrm{t} / \mathrm{a}$ & WtE 90's & WtE now & $\begin{array}{c}\text { SDI-FICFB + } \\
\text { ADOS-CHP }\end{array}$ & $\begin{array}{c}\text { SDI-FICFB + } \\
\text { ADOS+CCU }\end{array}$ \\
\hline aux. fuel & $800,000 \mathrm{GJ}$ & $0 \mathrm{GJ}$ & $0 \mathrm{GJ}$ & $0 \mathrm{GJ}$ \\
\hline $\begin{array}{c}\text { Electricity } \\
(€ 44 / \mathrm{MWh})\end{array}$ & $40,000 \mathrm{MWh}$ & $67,600 \mathrm{MWh}$ & $\begin{array}{c}105,900- \\
210,000 \mathrm{MWh}\end{array}$ & $0-210,000 \mathrm{MWh}$ \\
\hline $\begin{array}{c}\text { Heat } \\
(€ 15 / \mathrm{MWh})\end{array}$ & $470,000 \mathrm{MWh}$ & $426,400 \mathrm{MWh}$ & $\begin{array}{c}324,400- \\
405,000 \mathrm{MWh}\end{array}$ & $\begin{array}{c}192,750- \\
405,000 \mathrm{MWh}\end{array}$ \\
\hline $\begin{array}{c}\text { Synth. Fuel } \\
(\mathrm{U} \$ 100 / \mathrm{bbl})\end{array}$ & $0 \mathrm{bbl}$ & $0 \mathrm{bbl}$ & $78,400-0 \mathrm{bbl}$ & $205,000-0 \mathrm{bbl}$ \\
\hline$€_{\text {rev } / \mathrm{t} \mathrm{MSW}}$ & -42.38 & 35.49 & $71.06-63.36$ & $102.07-63.36$ \\
\hline
\end{tabular}

\section{$4 \quad 1^{\text {st }}$ time implementation of CCU innovation in MSW application}

So far we have mainly observed mainly technology-driven lighthouse projects, often started without a tangible roll-out plan or total financing in place. Therefore lack of headroom for obligatory learning curves often sacrificed good concepts, needing alignments or optimization into its full range of applications.

Furthermore we could observe in almost any high impact innovation undertaking that the implementation success heavily depended on the formation of consortia which cover the total supply chain affected and/or concerned. In some countries like Japan or Korea such initiatives are even installed by the Industry Ministry, in other industries like for example the HFC-Vehicle implementation OEMs and their module suppliers had to learn the hard way that they needed to join forces.

Therefore we would like to bring together a consortium of supply chain partners delivering input, cross-license producing output and grant off-taking output. By committing to jointly invest $40 \%$ of equity needed for a minimum 10 -fold roll-out over at least 6 countries after full validation by a small scale demonstration, each local consort group could get one of the 10 reference plants at an equity investment equivalent less than $15 \%$ of the expected capital expenditure of such plant and become sub-licensor in its territory and/or industry.

With the right consorts in the team, small scale demonstration could be financed through venture capital, to be attracted by the market placement power and competence represented by this new waste management approach's pioneer consortium [32].

\subsection{Market criteria}

Once hydrocarbon transformation by these waste to value concepts will break into MSW management, waste and energy will become the same category [33]. 


\section{References}

[1] "Clean Air Act's Implementing Rules and Regulations", Rule 28, Philippines

[2] http://www.kleanindustries.com/s/Home.asp

[3] http://www.alternrg.com/waste_to_energy/waste-to-liquids/

[4] http://www.enerkem.com/en/facilities/overview.html\#

[5] http://www.ineos.com/en/businesses/INEOS-Bio/Technology/\# Technology-Platform

[6] http://fulcrum-bioenergy.com/process.html

[7] Hofbauer, Koch, Aichernig; OUI Biomasse, Straßburg, Nov. 2013 p. 5, 10

[8] Zoltan Kish; ISWA 2013 Vienna, Oct. 2013

[9] Jan Peter Horn; SGC 2013 Goteborg, Oct. 2013

[10] http://www.coskata.com/process/

[11] http://www.icminc.com/images/pdfs/brochures/icm_advgas_bro $\% 20-\% 20$ 0412_digital.pdf

[12] R. Rauch; IEA Task 33 Status of Gasification adhesive Technologies, REECO 2013, Nov. 2013

[13] http://www.gpa-pyrolyse.com/english/company/

[14] http://www.exaenergie.com/

[15] http://www.energylifegroup.it/en/energy_platform.html

[16] http://www.ecoeng.eu/tecnologie/gasogeno/

[17] www.luxorka.sk

[18] http://www.dron-sklady.sk/lang2/index.html

[19] T. Shinagawa; JFE Gasifier for WtE in desalination; WFES 2014, Jan. 2014

[20] N. Dahmen; Synthetic fuels and chemical from biomass by the bioliqprocess; SGC 2013 Goteborg, Oct. 2013

[21] B. Fredriksson Möller, A. Horvath; E.ON Gasification Development, SGC 2013 Goteborg, Oct. 2013; ICPS 2013 Vienna, Sept. 2013

[22] World Bank; Global Review of Solid Waste Management, Urban Development Series 2012

[23] Åsa Burman; The GoBiGas-project, SGC 2013 Goteborg, Oct. 2013

[24] M. Bessières; Gaz de France Suez, ICPS 2013 Vienna, Sept. 2013

[25] H. Hofbauer, S. Fürnsinn, G. Bauer, C. Heilig, C. Aichernig; BMVIT Energy \& Environmental R\&D report 43/2009

[26] V. Wilk, R.Rauch, H. Hofbauer; "Methane Production from woody biomass", Biofuel Conference Berlin 2012

[27] Muradov, N., Thermocatalytic decomposition of methane using fixed bed reactor, Proc. 1996 U.S. DOE Hydrogen Prog. Rev., Miami, 1996

[28] EP 1623957 to Mauthner, Hammel et al.

[29] K. Mauthner; BMVIT Report 1/2011, Factory of the Future, EU-FP5

[30] H.J. Glinz, Carbon Capture for Products, Wietersdorfer Gruppe, $\mathrm{CO}_{2}$ Symposium Linz, Nov. 2012

[31] S. Petters, M. Fuchs, K. Mauthner; ISWA 2013, Vienna; Potential Economics from Waste's Carbon recycling

[32] S. Petters; ICON 2014 Investment Forum Vienna; April 2014

[33] HSBC advertisement postulate at airport gangways 